\title{
Article \\ Structural and Functional Behaviour of Ce-Doped Wide-Bandgap Semiconductors for Photo-Catalytic Applications
}

\author{
Giulia Forghieri ${ }^{1}$, Danny Zanardo ${ }^{1}$, Elena Ghedini ${ }^{1}$, Federica Menegazzo ${ }^{1}{ }^{1}$, Alessia Giordana ${ }^{2}$, \\ Giuseppina Cerrato $^{2}\left(\mathbb{D}\right.$, Alessandro Di Michele ${ }^{3}\left(\mathbb{D}\right.$, Giuseppe Cruciani ${ }^{4}\left(\mathbb{D}\right.$ and Michela Signoretto ${ }^{1, *(\mathbb{1}}$
}

1 CatMat Lab, Department of Molecular Sciences and Nanosystems, Ca' Foscari University of Venice and Consortium INSTM RU Ve, via Torino 155, 30172 Venice, Italy; giulia.forghieri@unive.it (G.F.); danny.zanardo@unive.it (D.Z.); gelena@unive.it (E.G.); fmenegaz@unive.it (F.M.)

2 Department of Chemistry and NIS Interdept, University of Turin, and Consortium INSTM RU TO via Pietro Giuria 7, 10125 Turin, Italy; alessia.giordana@unito.it (A.G.); giuseppina.cerrato@unito.it (G.C.)

3 Department of Physics and Geologia, University of Perugia, via Pascolo 1, 06123 Perugia, Italy; alessandro.dimichele@unipg.it

4 Department of Physics and Earth Sciences, University of Ferrara, via G. Saragat 1, 44122 Ferrara, Italy; cru@unife.it

* Correspondence: miky@unive.it

Citation: Forghieri, G.; Zanardo, D.; Ghedini, E.; Menegazzo, F.; Giordana A.; Cerrato, G.; Di Michele, A.; Cruciani, G.; Signoretto, M. Structural and Functional Behaviour of Ce-Doped Wide-Bandgap Semiconductors for Photo-Catalytic Applications. Catalysts 2021, 11, 1209. https://doi.org/10.3390/catal1110 1209

Academic Editors: Leonarda Francesca Liotta and Valeria La Parola

Received: 28 July 2021

Accepted: 1 October 2021

Published: 9 October 2021

Publisher's Note: MDPI stays neutra with regard to jurisdictional claims in published maps and institutional affiliations.

Copyright: (c) 2021 by the authors. Licensee MDPI, Basel, Switzerland. This article is an open access article distributed under the terms and conditions of the Creative Commons Attribution (CC BY) license (https:// creativecommons.org/licenses/by/ $4.0 /)$.

\begin{abstract}
Increasing the photocatalytic efficiency of earth-abundant wide-bandgap semiconductors is of high interest for the development of cheap but effective light-driven chemical conversion processes. In this study, the coupling of $\mathrm{ZnO}$ and $\mathrm{TiO}_{2}$ with low contents of the rare-earth Ce species aimed to assess the photo-catalytic performance of the two semiconductors (SC). Structural and optical characterizations were performed to estimate the effect of the different interactions between $\mathrm{Zn}^{2+}$, $\mathrm{Ti}^{4+}$ and $\mathrm{Ce}^{4+}$ ions, and how the photo-responsive behaviour of $\mathrm{Ce}-\mathrm{Ti}$ and $\mathrm{Ce}-\mathrm{Zn}$ composites was affected. Therefore, photo-catalytic tests were performed for all Ce-modified SC to assess both their photo-oxidative and photo-reductive properties. Amongst all the tested materials, only Zn-based samples resulted in being suitable for the photo-oxidation of the methylene blue (MB) organic pollutant in a synthetic-dependent fashion.
\end{abstract}

Keywords: rare earth; nanomaterials; carbon dioxide

\section{Introduction}

Since it was first introduced, the light-mediated catalytic conversion of many organic and inorganic molecules-also referred as photocatalysis-has become increasingly attractive, especially in the context of energy transition [1]. Therein, photocatalysis was widely employed for both photo-oxidation, such as photo-degradation of water pollutants, and photo-reductive reactions, such as the $\mathrm{CO}_{2}$ reduction or $\mathrm{H}_{2}$ production from water splitting [2], which were extensively studied mainly in wide-bandgap semiconductors [1,3]. In this context, photocatalysis refers to the ability of a semiconductor (SC) to employ the energy of incident photons to form new chemical bonds in a chemical redox reaction via electrons or holes transfer. In fact, when the energy of photons is equal or greater than the semiconductor's bandgap, an electron-hole pair is generated, which can either recombine or transfer to an acceptor molecule, thereby initiating the oxidizing or reducing process [3].

An effective light-to-chemical conversion generally relies on both charge transfer and charge mobility, which in turn, may be affected by several factors, such as electron mobility, recombination rate and defects density in the material [3,4]. In addition, when dealing with heterogeneous catalysis, either in gaseous or liquid media, other parameters become relevant for the catalytic performance, including the mass, the surface area and presence of active sites of the catalyst, the wavelength employed, the initial concentration of the contaminant, the temperature and the pressure of oxygen, if present [5]. 
The application of SCs, such as $\mathrm{TiO}_{2}, \mathrm{ZnO}, \mathrm{CeO}_{2}$, or CdS, as well as many others, for the treatment of air pollutants has been proposed and studied for both outdoor and indoor applications for the photocatalytic oxidation of $\mathrm{VOCs}, \mathrm{NO}_{\mathrm{x}}, \mathrm{SO}_{\mathrm{x}}, \mathrm{CO}$, and other organic molecules, as well as in the photoreduction of $\mathrm{CO}_{2}$ and $\mathrm{H}_{2} \mathrm{O}[1,5,6]$.

The employment of $\mathrm{TiO}_{2}$ and $\mathrm{ZnO}$-based catalysts was widely addressed for their non-toxicity, availability and low cost, with a focus on $\mathrm{TiO}_{2}$, regarding its photochemical stability and high photoactivity $[1,6] . \mathrm{TiO}_{2}$ is an n-type and indirect band-gap semiconductor with unique scattering properties [7]. It is present in four different crystallographic phases, namely rutile (tetragonal), anatase (tetragonal), brookite (orthorhombic) and $\mathrm{TiO}_{2}-\mathrm{B}$ (monoclinic) [3]. Rutile and anatase phases consist of octahedrons, in which each Ti atom is surrounded by six oxygen atoms, whose structure is differently organised according to the phase. The two polymorphs were mostly investigated for their photocatalytic activity, owing to the inter-band transition occurring with energies belonging to the near UV region [8]. Thermal stability, recombination rate, and charge mobility are also different in the two polymorphs, with anatase showing a lower thermal stability, but also a lower recombination rate [8].

$\mathrm{ZnO}$ is a direct bandgap, II-VI semiconductor with each atom spatially organized to form a tetrahedron, binding by turn four other atoms, and wurtzite being the phase most commonly stable at atmospheric pressure conditions [9]. Together with a slightly broader bandgap, the higher electron mobility and exciton binding energy of $\mathrm{ZnO}$ results in a lower recombination rate and suggests a greater photocatalytic potential when compared to $\mathrm{TiO}_{2}$ [9]. Nanostructured $\mathrm{ZnO}$ has been mainly employed for photo-driven oxidative reactions, such as pollutants or dye degradation in water [10,11], but also as a anti-microbial and anti-cancer agent, owing to reported cytotoxic properties [12]. Nevertheless, the role of $\mathrm{ZnO}$ as a promising photocatalyst is currently mainly limited by photo-corrosion upon UV-light exposure and absorption in only the UV region of the sun light spectrum [10].

The introduction of lanthanides $\mathrm{Ln}^{3+}$-also known as rare-earths-such as $\mathrm{La}^{3+}, \mathrm{Eu}^{3+}$, $\mathrm{Pr}^{3+}, \mathrm{Nd}^{3+}$ and $\mathrm{Sm}^{3+}$ in $\mathrm{TiO}_{2}$ semiconductor was reported to increase the adsorption of organic molecules, and proposed to improve both the photocurrent response, the UV incident photon to current conversion and the photocatalytic removal of organic air pollutants $[13,14]$. All these features were mainly attributed to increased specific surface, formation of mixed oxides and SC heterojunctions, and the presence and amount of $\mathrm{Ti}^{3+}$ recombination centres [14]. In this regard, the introduction of $\mathrm{CeO}_{2}$ in either $\mathrm{TiO}_{2}$ or $\mathrm{ZnO}$ based materials, to form $\mathrm{CeO}_{2} / \mathrm{TiO}_{2}$ or $\mathrm{CeO}_{2} / \mathrm{ZnO}$-mixed oxides composites, was also shown to reduce the bandgap, thereby also promoting a visible light-driven degradation of organic compounds, the latter also depending on $\mathrm{Ce} / \mathrm{Ti}$ and $\mathrm{Ce} / \mathrm{Zn}$ molar ratios $[13,15]$. Cerium is the most abundant rare-earth element [16], mainly present as $\mathrm{CeO}_{2}$ with a cubic fluorite and $\mathrm{Ce}_{2} \mathrm{O}_{3}$ with a hexagonal structure [17], and characterized by non-toxicity, high UV-extinction coefficient and oxygen storage ability, according to its chemical potential, previously related to the co-existence of both $\mathrm{Ce}^{3+}$ and $\mathrm{Ce}^{4+}$ oxidation states in the same material [18], with $\mathrm{Ce}^{3+}$ species being mainly localized at the surface [19].

The band gap of bulk $\mathrm{CeO}_{2}$ was reported to be $\sim 3.2 \mathrm{eV}$, for which the O-2p to Ce- $4 \mathrm{f}$ transition accounts, and to increase by decreasing the particle size, due to both a quantum confinement and a cluster effect [20]. However, the band gap was elsewhere reported as $\sim 2.8 \mathrm{eV}$ and potentially related to the stoichiometric ratio between $\mathrm{CeO}_{2}$ and $\mathrm{Ce}_{2} \mathrm{O}_{3}$ oxides [19].

$\mathrm{CeO}_{2}$ is broadly employed as a polishing agent and a glass constituent [16], while nanostructured $\mathrm{CeO}_{2}$ has been mainly proposed as a UV-filter, as a reactive oxygen species (ROS) inactivator, or for drug delivery purposes in biological systems, although its photocatalytic activity has also been proven [21].

For instance, $\mathrm{CeO}_{2}-\mathrm{ZnO}$ composites showed increased photocatalytic activity compared to bare $\mathrm{ZnO}, \mathrm{CeO}_{2}$ and $\mathrm{TiO}_{2}$ in the photo-degradation of water pollutants under visible $[13,22]$ or UV light [23]. Notably, the $\mathrm{CeO}_{2} / \mathrm{ZnO}$ oxides ratio was related to the presence of defects and heterojunctions, which were suggested to decrease the electron-hole pairs 
recombination rate, improve the stability [13], and modify the adsorbing properties of the material [24,25]. Metal-doped $\mathrm{CeO}_{2}$ showed high photocatalytic and supercapacitor properties when used as a photoelectrode [26]. Similarly, $\mathrm{CeO}_{2} / \mathrm{ZnO}$ systems were also employed as photoanodes and proposed for the electro-detection of organic molecules [13]. Nevertheless, still little is known about the employment of such composites in the photo-degradation of water pollutants, as well as $\mathrm{CO}_{2}$ photoreduction, although porous $\mathrm{CeO}_{2} / \mathrm{ZnO}$ binary oxides were reported for the photo-oxidation of $\mathrm{CO}$ [27]. Conversely, $\mathrm{CeO}_{2}-\mathrm{TiO}_{2}$ systems were successfully employed to photo-convert gaseous $\mathrm{CO}_{2}$ into $\mathrm{CH}_{3} \mathrm{OH}$ [17], as well as for the photo-degradation of organic pollutants using UV and visible light [15,28]. Moreover, $\mathrm{CeO}_{2}-\mathrm{TiO}_{2}$ mixed systems loaded with $\mathrm{Pt}$ or $\mathrm{Au}$ were reported for $\mathrm{H}_{2}$ production in the photo-driven $\mathrm{H}_{2} \mathrm{O}$ splitting upon visible and UV light exposure, respectively $[29,30]$. The presence of $\mathrm{CeO}_{2}$ was also found to improve the light-harvesting efficiency in $\mathrm{TiO}_{2}$-based dye-sensitized solar cells [31]. The aim of this study was to synthesize $\mathrm{CeO}_{2}-\mathrm{TiO}_{2}$ and $\mathrm{CeO}_{2}$-ZnO-mixed oxides by means of a co-precipitation method using two different precipitating agents, to investigate both the structural and optical effect due to the introduction of cerium species over the photo-catalytic performance of earth-abundant metal oxides. In particular, the purpose was to relate the effect of structural and optical properties of the composite materials to the photocatalytic activity. The materials were therefore tested for the $\mathrm{H}_{2} \mathrm{O}$-mediated photoreduction of $\mathrm{CO}_{2}$ and for the photo-oxidation of a dye model pollutant methylene blue (MB) under UV light irradiation.

\section{Results and Discussion}

\subsection{Photocatalytic Activity}

The photo-driven reduction ability of CZ20, CCZ20 and CT20 was compared to a lab-prepared nanosized $\mathrm{ZnO}$ and a commercial $\mathrm{TiO}_{2}$ (P25, Evonik), and it is reported in Figure S1 of SI. Samples were tested in gas phase in a $\mathrm{CO}_{2}$-rich environment both to favour the production of $\mathrm{CH}_{4}$ over the side formation of $\mathrm{H}_{2}$ and to maximized $\mathrm{CO}_{2}$ availability [32]. Results showed no $\mathrm{CO}_{2}$ photo-driven conversion for any of the Ce-containing composites, while both bare $\mathrm{ZnO}$ and $\mathrm{TiO}_{2}$ were able to produce $\mathrm{CH}_{4}$ in the tested conditions (Figure S1 of SI). The photo-oxidative properties of the samples were tested on MB degradation tests. Samples were tested in aqueous medium without the addition of salts to avoid side effects and to provide model conditions, in order to highlight the performance of the catalysts and facilitate their comparison. When exposed to light, the mixed oxides samples CZ20 and CCZ20 showed an effective catalytic activity over $1 \mathrm{~h}$. However, the latter was still lower than bare $\mathrm{ZnO}$, as shown by the evolution of the relative concentration $\mathrm{C} / \mathrm{C}_{0}$ in Figure 1. CCZ20 showed higher catalytic performance than CZ20, while CT20 showed no photo-oxidative activity in the tested conditions.

\subsection{Effect of Ce-Doping on the Structure}

The effect of cerium on the structure and morphology of $\mathrm{TiO}_{2}$ and $\mathrm{ZnO}$ semiconductors was investigated by PXRD, Raman spectroscopy, imaging and physisorption techniques, to correlate these properties to the photocatalytic performance of the materials.

XRD analysis of CCZ20 and CZ20 samples revealed the characteristic pattern of wurtzite, with a hexagonal unit cell [10], confirmed by the peaks located at 32.1 (010), 34.5 (002), 36.5 (011), 67.1 (020), 68.5 (112), 69.9 (021) (Figure 2), as well as the presence of cerianite as cubic fluorite, identified by the star in Figure 2, and confirmed by the broadening of the $\mathrm{ZnO}$ peaks at $2 \theta=47.79^{\circ}$ and at $2 \theta=57.16^{\circ}$, as already reported [27]. The Rietveld analysis for CZ20 and CCZ20 revealed a difference in the crystallite size of zincite, found to be $\sim 80 \mathrm{~nm}$ and $\sim 20 \mathrm{~nm}$ respectively, and attributed to the employment of different precipitating agents. Therefore, the presence of smaller $\mathrm{CeO}_{2}$ cubic fluorite crystallites $(\sim 3 \mathrm{~nm})$ dispersed in the $\mathrm{ZnO}$ structure (Figure 2) was hypothesized rather than the substitution of $\mathrm{Ce}^{4+}$ ions to the $\mathrm{Zn}^{2+}$ ones [33]. 


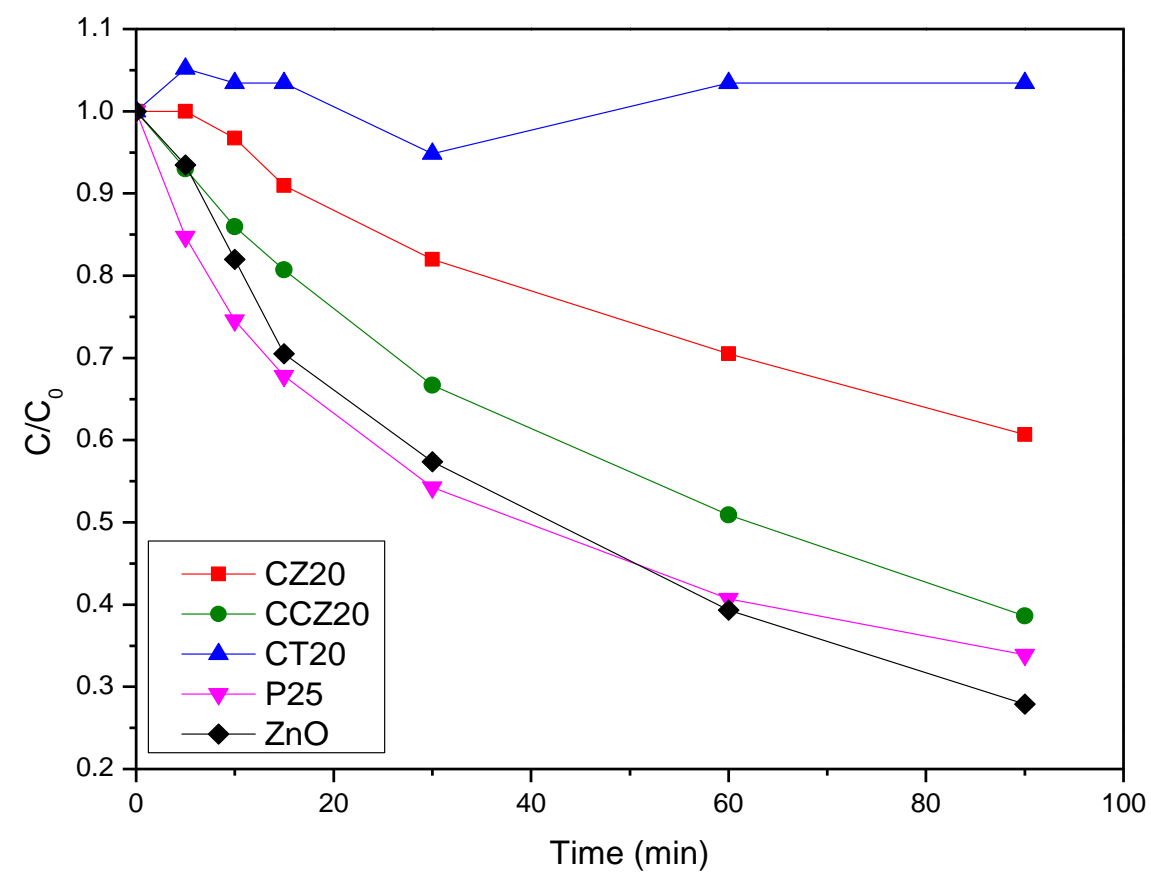

Figure 1. Time evolution of $\mathrm{MB}$ relative concentration $\mathrm{C} / \mathrm{C}_{0}$ during the photo-catalytic tests of the composite samples under UV light irradiation.

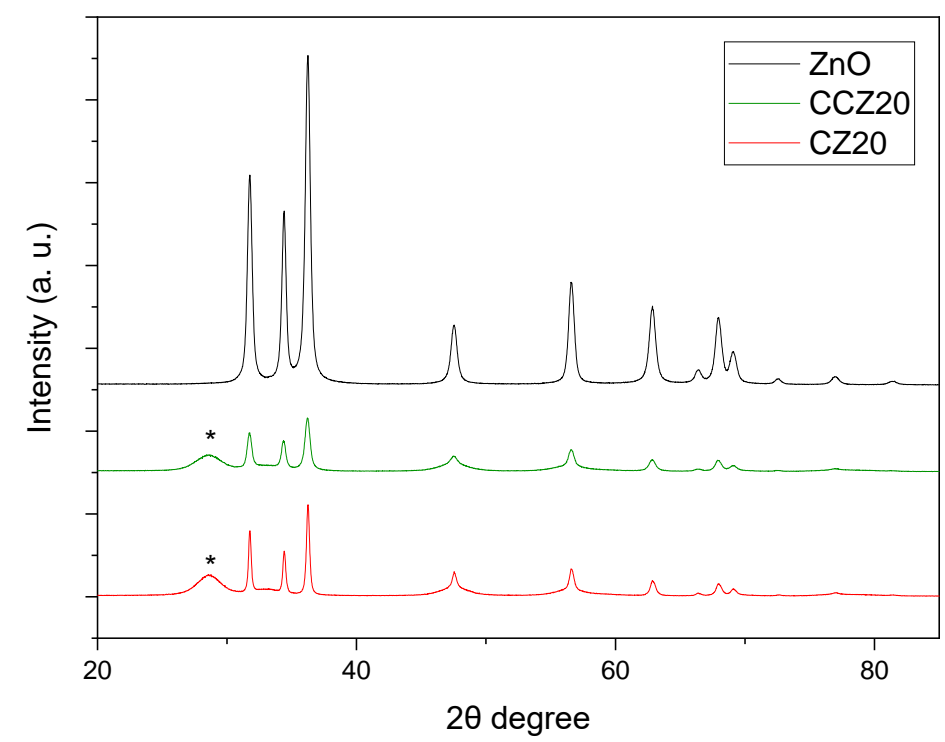

Figure 2. XRD pattern of bare $\mathrm{ZnO}$ and $\mathrm{CeO}_{2}-\mathrm{ZnO}$ precipitated with carbonates $(\mathrm{CCZ} 20)$ and $\mathrm{NaOH}$ (CZ20).

The $\mathrm{CeO}_{2}$ and $\mathrm{TiO}_{2}$ crystal patterns were not clearly detected after XRD analysis of CT20, which revealed an amorphous pattern characterized by a broad peak at $30^{\circ}$ (Figure 3 ). Such an amorphous structure could partially explain the decrease of the catalytic activity of the material. The formation of cerium titanate $\mathrm{Ce}_{\mathrm{x}} \mathrm{Ti}_{(1-x)} \mathrm{O}_{2}$ in the $\mathrm{TiO}_{2}$ phase [28] was previously reported, as a result of the presence of a hetero-structure as a new phase, but no evidence of this phase is found in our sample. 


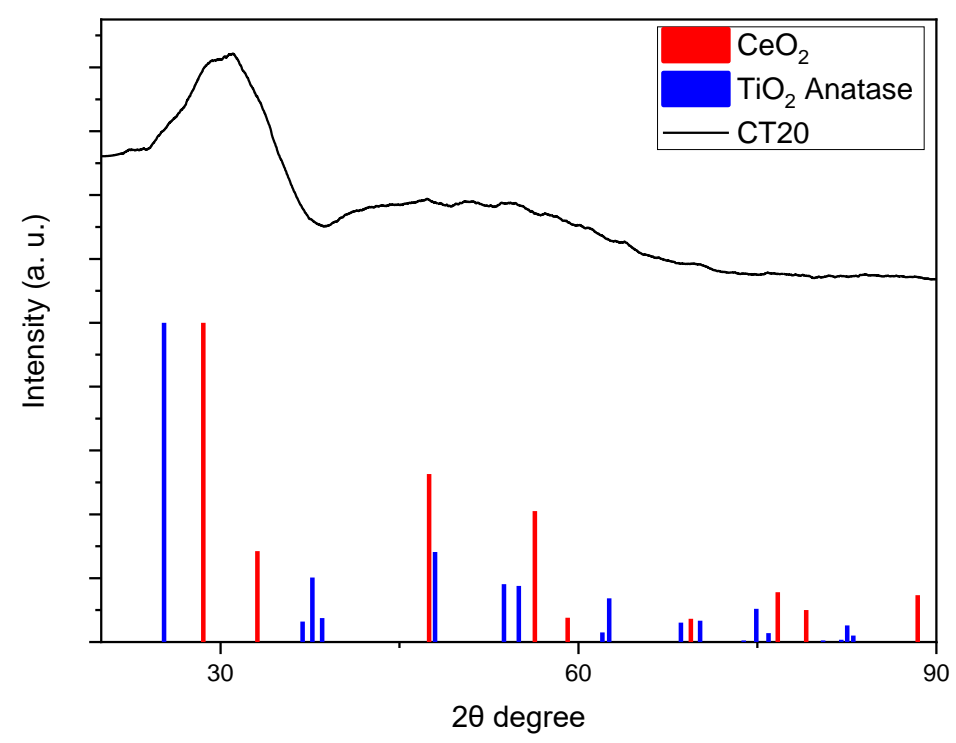

Figure 3. XRD Pattern of CT20. Blue and red lines show the cerianite-, cubic fluorite- and anataserelated crystallographic peaks.

Raman spectroscopy is an efficient tool for the structural characterization of SC. In the Raman spectra of CZ20 and CCZ20, it was possible to recognize signals of both components (Figure 4). The low-intensity band at $100 \mathrm{~cm}^{-1}$ is attributed to $\mathrm{ZnO}$, whose characteristic pattern consisted of the two signals located at $100 \mathrm{~cm}^{-1}$ and $438 \mathrm{~cm}^{-1}$ [34], while the strong band at $460 \mathrm{~cm}^{-1}$ is attributed to ceria. The asymmetric broadening of this last band indicates the presence of small $\mathrm{CeO}_{2}$ nanoparticles dispersed in the $\mathrm{ZnO}$ structure [35], as hypnotised by XRD analysis. It can be notice that CZ20 has an intense fluorescence above $1000 \mathrm{~cm}^{-1}$, probably correlated with a higher concentration of defects, which are in turn responsible of the luminescence phenomenon, on smaller particles [36]. The sample CT20 also presents a very fluorescent Raman spectrum, and only a sharp signal at $140 \mathrm{~cm}^{-1}$ can be recognized. This strong signal is characteristic of anatase phase, typical of $\mathrm{TiO}_{2}(\mathrm{P} 25)$ (whose spectrum is shown in Figure 4), but due to the amorphous nature of our sample, could be better ascribed to Ti-O stretching mode. In this case, the luminescence of CT20 could be also correlated to the amorphous nature of the obtained small nanoparticles.

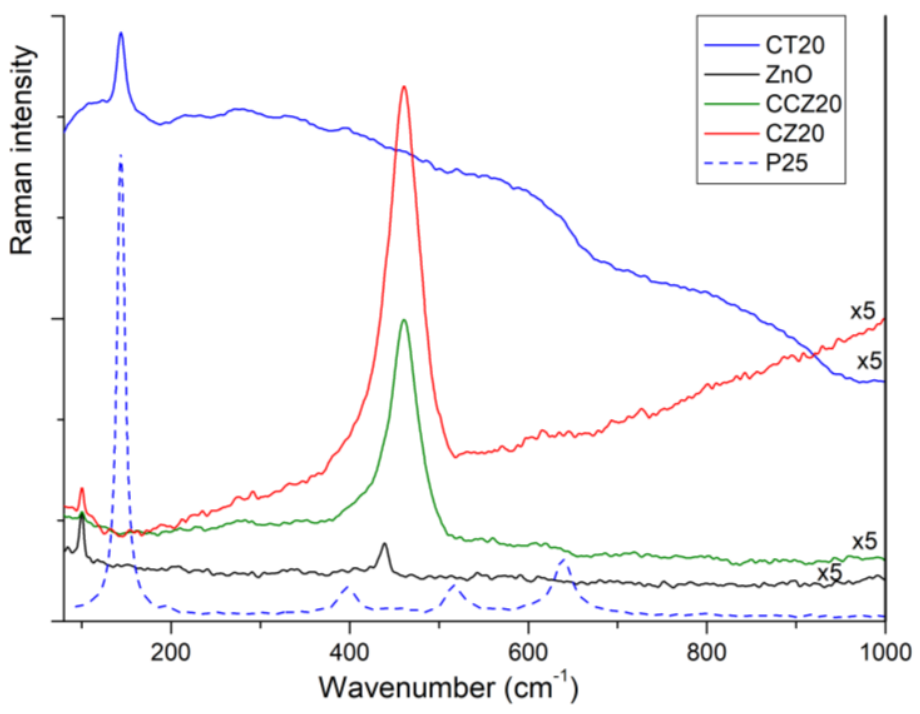

Figure 4. Raman spectra of pristine and doped materials. 
The $\mathrm{N}_{2}$ physisorption analysis showed an increase in surface area upon introduction of cerium. The BET-specific surface area of CCZ20 was both higher than bare $\mathrm{ZnO}$ and CZ20, as reported in Table 1. This difference was again attributed to the use of different precipitating agents. The sample CT20 showed a considerably higher specific surface area compared to the commercial standard (P25) one, as shown in Table 1. The isotherm of CCZ20 was found to be typical of macro-mesoporous materials and comparable to bare $\mathrm{ZnO}$ (Figure 5), while the type IV isotherms exhibited by CT20 indicated a clearly mesoporous profile with an average pore diameter of $\sim 8 \mathrm{~nm}$ (Figure S3 in SI). Conversely, the small hysteresis in the CZ20 isotherm suggested a very low porosity of the composite material (Figure 5).

Table 1. BET-specific surface area of bare and $\mathrm{CeO}_{2}$-doped samples.

\begin{tabular}{cc}
\hline Sample & Specific Surface Area $\left(\mathbf{m}^{\mathbf{2}} \mathbf{g}\right)$ \\
\hline $\mathrm{TiO}_{2}(\mathrm{P} 25)$ & 50 \\
\hline $\mathrm{ZnO}$ & 25 \\
\hline $\mathrm{CT} 20$ & 162 \\
\hline $\mathrm{CZ} 20$ & 25 \\
\hline $\mathrm{CCZ} 20$ & 42 \\
\hline
\end{tabular}

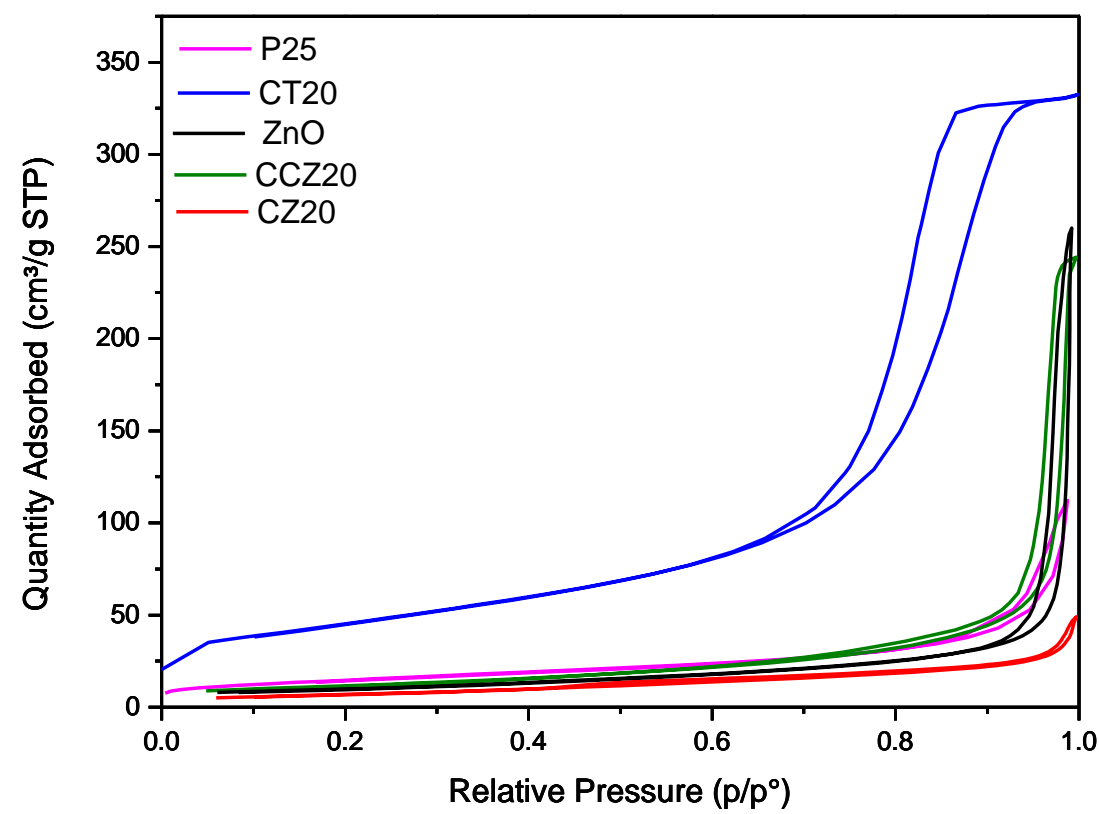

Figure 5. Comparison of $\mathrm{N}_{2}$ physisorption isotherms of (black) bare $\mathrm{ZnO}$, (blue) P25, (black dash) CZ20, (black dot) CCZ20, and (blue dash) CT20.

SEM analysis of $\mathrm{ZnO}$ showed nanostructured aggregates with variable sizes, ranging from 30 to $50 \mathrm{~nm}$ (Figure S2 of Supporting Information, SI).

The cerium-containing composites obtained via co-precipitation method are depicted in Figure 6a-f. CZ20 and CCZ20 showed a remarkable difference in size, morphology and roughness at low magnification (Figure $6 a, c)$. The reported difference in crystallites dimension likely reflected the bigger size of CZ20 elongated structures, compared to the smaller spheroidal nano-sized particles of CCZ20, which showed instead an average diameter of $30 \mathrm{~nm}$ (Figure 6a-d). Similarly, the size of spheroidal $\mathrm{CeO}_{2}-\mathrm{TiO}_{2} \mathrm{NP}$, showing an average diameter of $12 \mathrm{~nm}$, likely supported an amorphous structure as the possible result of the different ionic radius of $\mathrm{Ce}^{4+}$ and $\mathrm{Ti}^{4+}$ (Figure 6e,f) [37]. The decreased particle dimensions, were correlated to the increased surface area, as reported by $\mathrm{N}_{2}$ physisorption. 

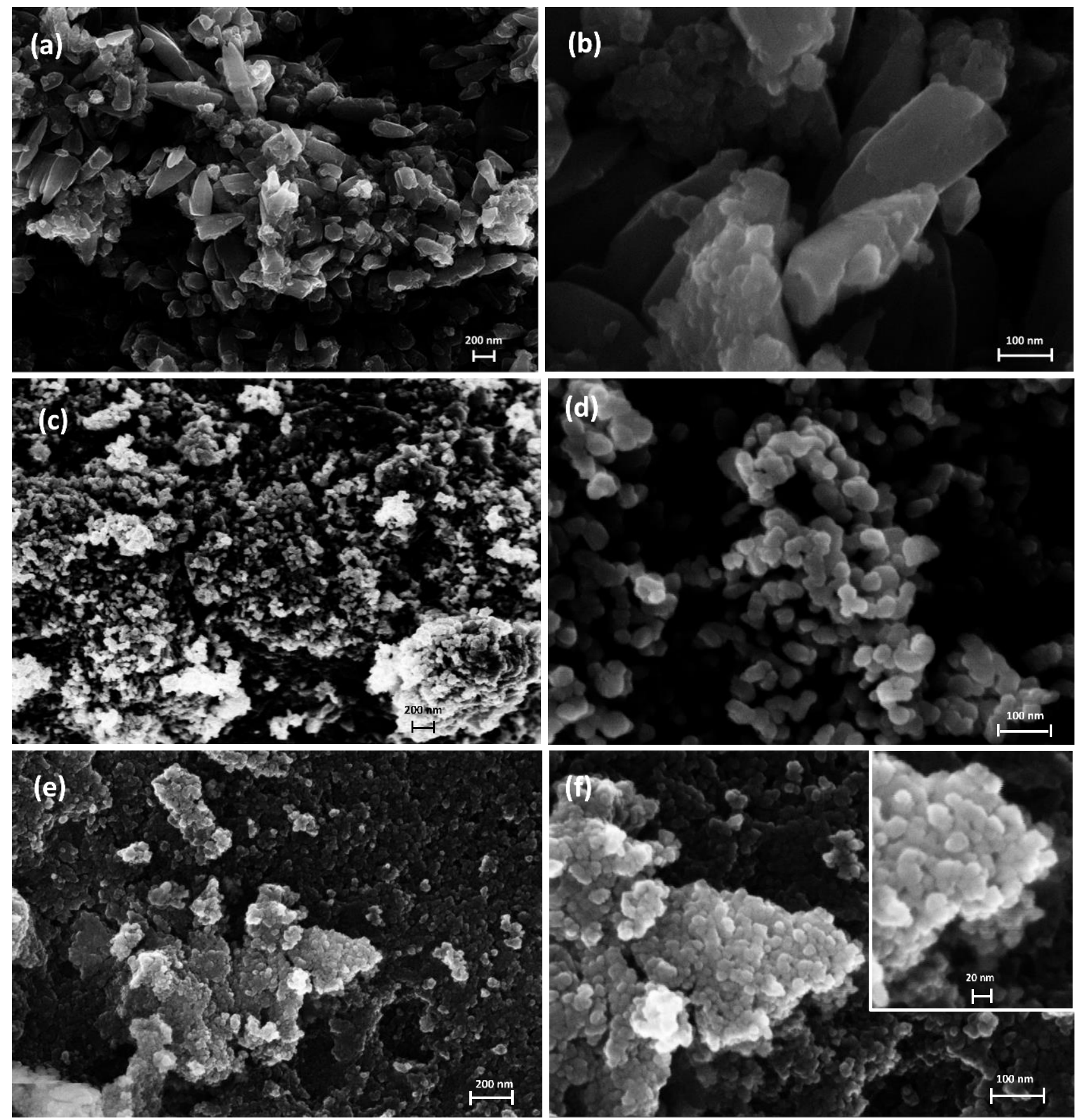

Figure 6. SEM analysis of (a,b) CZ20, (c,d) CCZ20 and (e,f) CT20 showing different roughness and size; spheroidal particles of (d) $30 \mathrm{~nm}$ and (f) $12 \mathrm{~nm}$ average diameter for CCZ20 and CT20 clusters.

The morphological properties of the cerium-containing samples were mainly ascribed to the employed synthetic technique and to the different $\mathrm{Zn}$ or Ti interactions with $\mathrm{Ce}^{4+}$ ions, resulting in two different crystal structures. In fact, the different precipitation conditions may have affected the structural features of the samples, also resulting in the different catalytic activity of CCZ20 and CZ20, as well as of CT20. In particular, it is proposed that the presence of carbonate species favoured a slower precipitation of $\mathrm{Ce}^{4+}$ and $\mathrm{Zn}^{2+}$ ions, with the consequent stabilization of Ce- $\mathrm{Zn}$ composites with homogeneous size and structure, also reflected in the different zincite crystallite sizes of CZ20 and CCZ20. On the other hand, the introduction of $\mathrm{Ce}^{4+}$ ions in the $\mathrm{TiO}_{2}$ structure resulted in lattice distortion and consequent smaller nanoparticle size, contributing to the amorphous phase and owed 
to the relevant difference in the ionic radius of $\mathrm{Ti}^{4+}(0.61 \AA)$, compared to both $\mathrm{Ce}^{4+}$ and $\mathrm{Zn}^{2+}$ ones, which exhibit larger radii as $0.87 \AA$ and $0.74 \AA$, respectively [37].

\subsection{Effect of Ce-Doping on the Functional and Optical Behaviour}

To investigate the influence of structural differences highlighted on the sample reducibility, TPR analyses were resorted on.

The $\mathrm{H}_{2}$-TPR results of CCZ20 and CZ20 showed a pronounced peak between $400{ }^{\circ} \mathrm{C}$ and $500{ }^{\circ} \mathrm{C}$ (Figure 7), which differed from the latter as a possible result of different $\mathrm{CeO}_{2}$ crystallite size and distribution. The increased presence and stability of surface $\mathrm{Ce}^{4+}$ species were related to the peak between $500{ }^{\circ} \mathrm{C}$ and $600{ }^{\circ} \mathrm{C}$ in $\mathrm{CZ} 20$, as bare $\mathrm{CeO}_{2}$ reduction profile is typically characterized by two broad peaks between $400^{\circ} \mathrm{C}$ and $600{ }^{\circ} \mathrm{C}$ and above $800^{\circ} \mathrm{C}$, attributed to surface and bulk $\mathrm{Ce}^{4+}$ to $\mathrm{Ce}^{3+}$ reduction, respectively [38]. Three main bands were detected in the CT20 reduction profile and attributed to a Ce-like and a Ti-like peak at $500{ }^{\circ} \mathrm{C}$ and $650{ }^{\circ} \mathrm{C}$ respectively, upon comparison with both bare $\mathrm{CeO}_{2}$ and $\mathrm{TiO}_{2}$ [39,40], and an intermediate component around $600{ }^{\circ} \mathrm{C}$, attributed to the synergic interaction of $\mathrm{Ce}^{3+}$ and $\mathrm{Ce}^{4+}$ ions, with $\mathrm{TiO}_{2}$ in the amorphous phase.

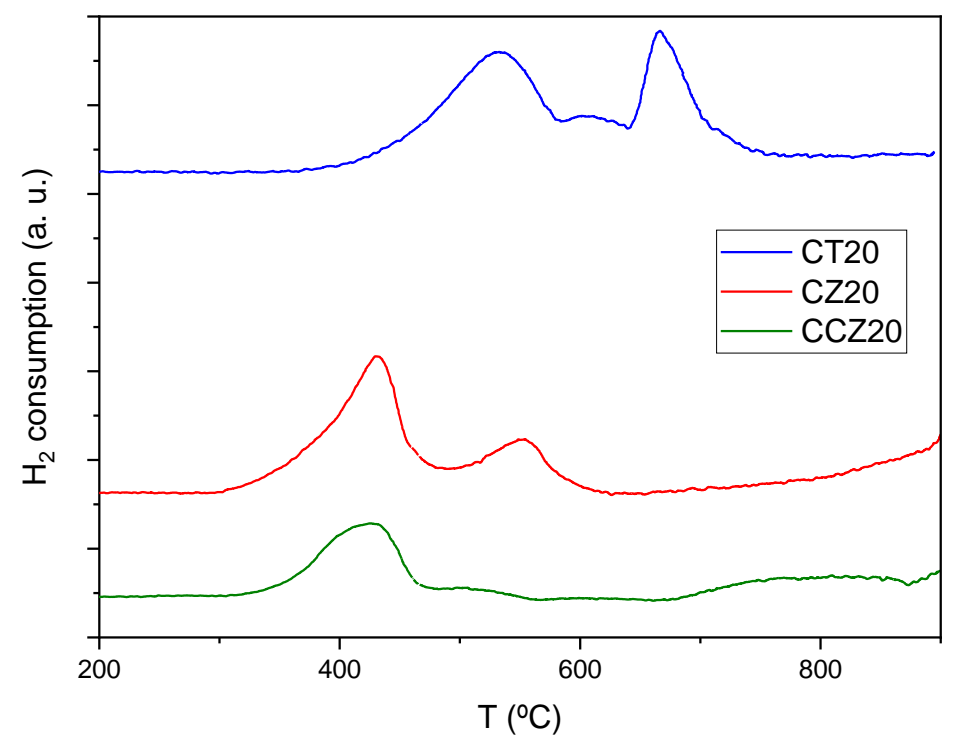

Figure 7. $\mathrm{H}_{2}$-TPR comparison of CCZ20, CCZ20 and CT20.

The attenuated total reflectance (ATR) spectroscopy was performed to evaluate the possible presence of species adsorbed at the surface and spectra of bare and doped materials, as shown in Figure 8. In the spectra of all samples, there is a broad band in the $3500-3000 \mathrm{~cm}^{-1}$ spectral range, attributed to the surface adsorbed water and to- $\mathrm{OH}$ functional groups, both interacting by hydrogen bonds. The presence of the corresponding $\delta(\mathrm{HOH})$ bending mode at $1630 \mathrm{~cm}^{-1}$ indicates that undissociated water molecules are present into and on the surface of the materials. These signals are more intense for $\mathrm{TiO}_{2}$-based samples. The bands observed in the $1600-1200 \mathrm{~cm}^{-1}$ spectral region can be associated to adsorbed carbonates species [41,42], and are more intense for bare $\mathrm{ZnO}-$ based materials. For CT20 sample, the presence of two bands at $1570 \mathrm{~cm}^{-1}$ and $1350 \mathrm{~cm}^{-1}$, absent in the spectrum of bare $\mathrm{TiO}_{2}$, suggests an increased affinity for carbonates adsorption by the doped material, that could be related to increased basicity of the sample due to the presence of cerium. A similar behaviour was observed for CCZ20, whose spectrum shows two bands at 1570 and $1350 \mathrm{~cm}^{-1}$, more intense than those of bare ZnO. CZ20 showed a different behaviour: bands related to absorbed water are very low, and a very different pattern is observed in spectral range $1600-1200 \mathrm{~cm}^{-1}$. The intense signals at $\approx 2900 \mathrm{~cm}^{-1}$ are attributable to stretching modes of aliphatic groups $\left(\mathrm{CH}_{\mathrm{x}}\right)$, whose corresponding bending modes are detectable around $1500 \mathrm{~cm}^{-1}$, while below $1200 \mathrm{~cm}^{-1}$, there are signals ascribable to $\mathrm{C}-\mathrm{C}$ stretching mode. As no templates were used in the synthetic procedure, 
it is possible that carbonaceous residuals were captured from the surrounding environment, including atmospheric $\mathrm{CO}_{2}$. The presence of surface-bound compounds could have reduced the hydrophilicity for CZ20 sample, thereby also affecting the photocatalytic activity. In fact, these features can limit the interaction with the medium and prevent the formation of reactive oxygen species, both in aqueous and gaseous media. Moreover, too strongly adsorbed C-based compounds could prevent the binding and release of the intermediate reagents, thereby affecting product formation, especially in the $\mathrm{CO}_{2}$ photo-reduction.

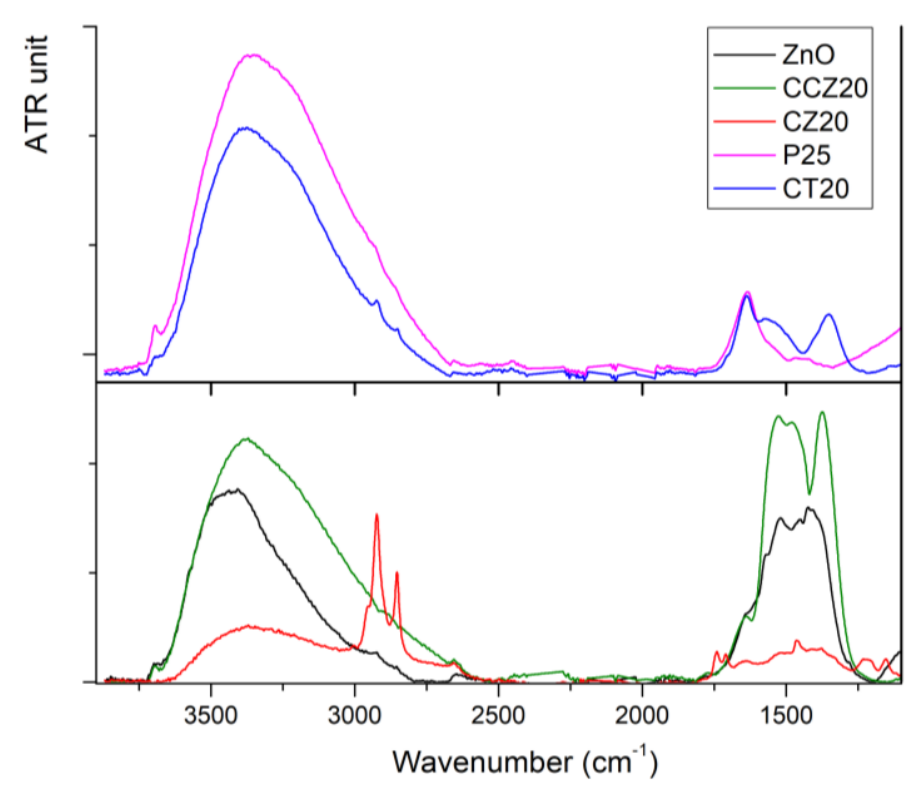

Figure 8. ATR spectra in the spectral range $3800-1000 \mathrm{~cm}^{-1}$.

Therefore, to further elucidate the presence of surface-adsorbed compounds, temperatureprogrammed analysis was performed.

The result of the He-TPD analysis of samples is reported in Figure 9. The peak detected at $290{ }^{\circ} \mathrm{C}$ for $\mathrm{ZnO}$ was attributed to surface-adsorbed carbonates, as suggested by ATR analysis, released with the temperature increase [43]. The TPD of CT20 showed a similar peak at $310^{\circ} \mathrm{C}$, and two other detectable bands at $350{ }^{\circ} \mathrm{C}$ and $600{ }^{\circ} \mathrm{C}$ attributed to the release of adsorbed carbonates and to the temperature-dependent reduction of superficial $\mathrm{Ce}^{4+}$ state into $\mathrm{Ce}^{3+}$, with consequent $\mathrm{O}_{2}$ release. The band found at around $600{ }^{\circ} \mathrm{C}$ in CZ20 was related to the decomposition of organic residual, in accordance with FTIR results. Conversely, CCZ20 only showed a broad band above $700{ }^{\circ} \mathrm{C}$, suggesting the possible presence of multiple adsorption sites with different binding affinity, as already suggested by ATR data.

Figure 10 shows the He-TPD of CT20 before and after exposure to $\mathrm{CO}_{2}$ gaseous pulses. The use of $\mathrm{CO}_{2}$ pulses aimed to identify and better discriminate amongst the potential $\mathrm{CO}_{2}$-binding sites in the materials, as observed in standard He-TPD (Figure 9). 


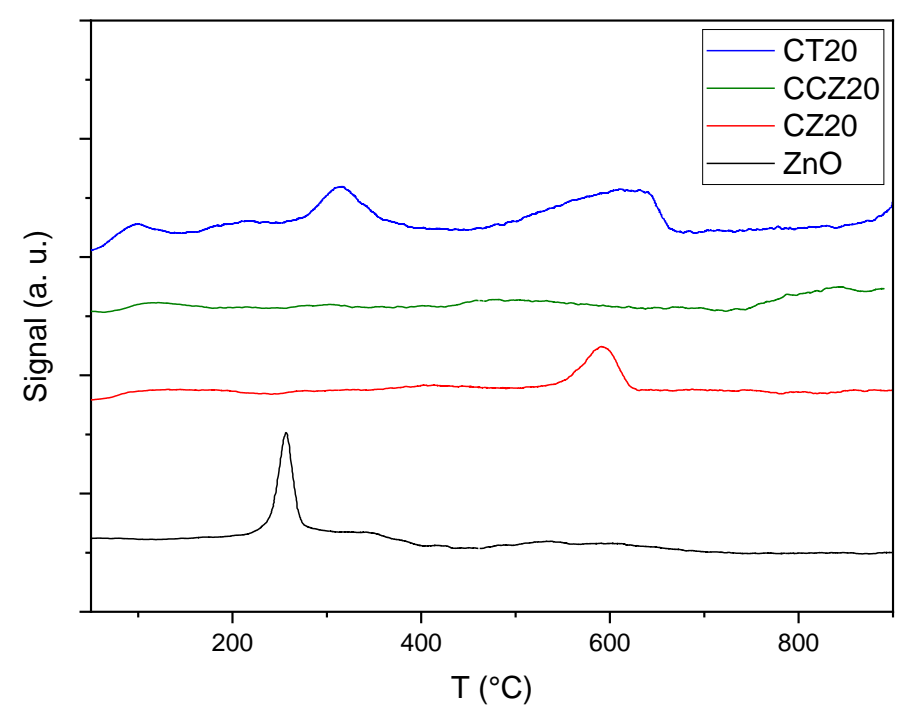

Figure 9. He-TPD of Ce-Zn composite.
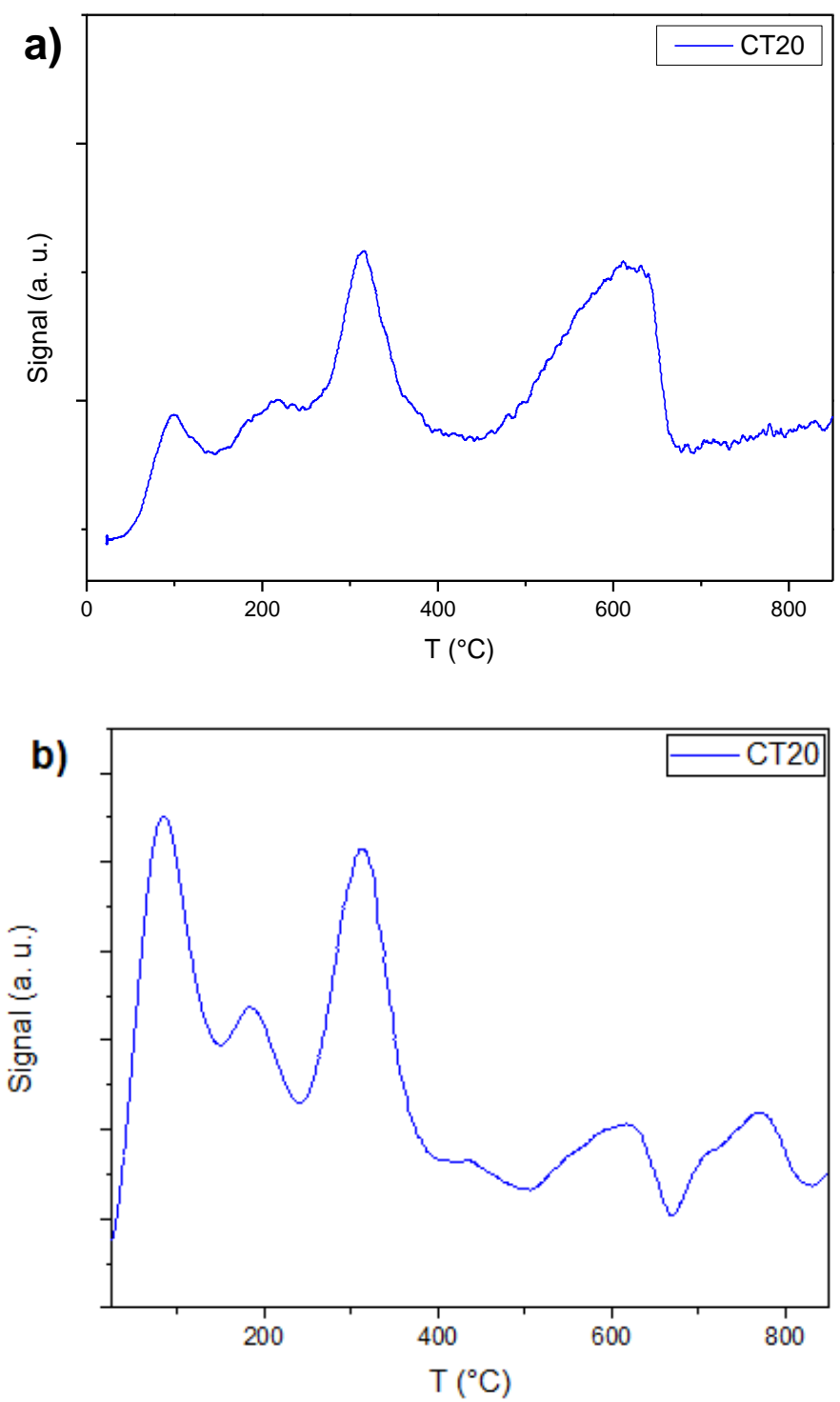

Figure 10. He-TPD of CT20 (a) before and (b) after exposure to a $\mathrm{CO}_{2}$-rich environment for $1 \mathrm{~h}$ at room temperature. 
The comparison of He-TPD (Figure 10a) and $\mathrm{CO}_{2}-\mathrm{TPD}$ (Figure 10b) showed an increase in the relative intensity of the peaks at $120^{\circ} \mathrm{C}$ and $350^{\circ} \mathrm{C}$, which were therefore attributed to $\mathrm{CO}_{2}$ release. Notably, the detection of a band between 700 and $800{ }^{\circ} \mathrm{C}$ after exposure to $\mathrm{CO}_{2}$ suggested the presence of surface regions able to strongly bind the molecule. As a consequence, the band centred at $650{ }^{\circ} \mathrm{C}$ was ascribed to the reduction of $\mathrm{Ce}^{4+}$ to $\mathrm{Ce}^{3+}$ species, leading to $\mathrm{O}_{2}$ release, as already reported [38]. These results supported the overall increased affinity for $\mathrm{CO}_{2}$, owing to the increased basicity of the material, as expected by introducing $\mathrm{CeO}_{2}$ and, as suggested, by ATR spectroscopy.

The optical behaviour of the synthesized materials was further elucidated by diffused reflectance spectroscopy (DRS) and photo-luminescence (PL) analysis.

Results obtained by DRS were converted and plotted, as shown in Figure 11, using the Kubelka-Munk function F(R).

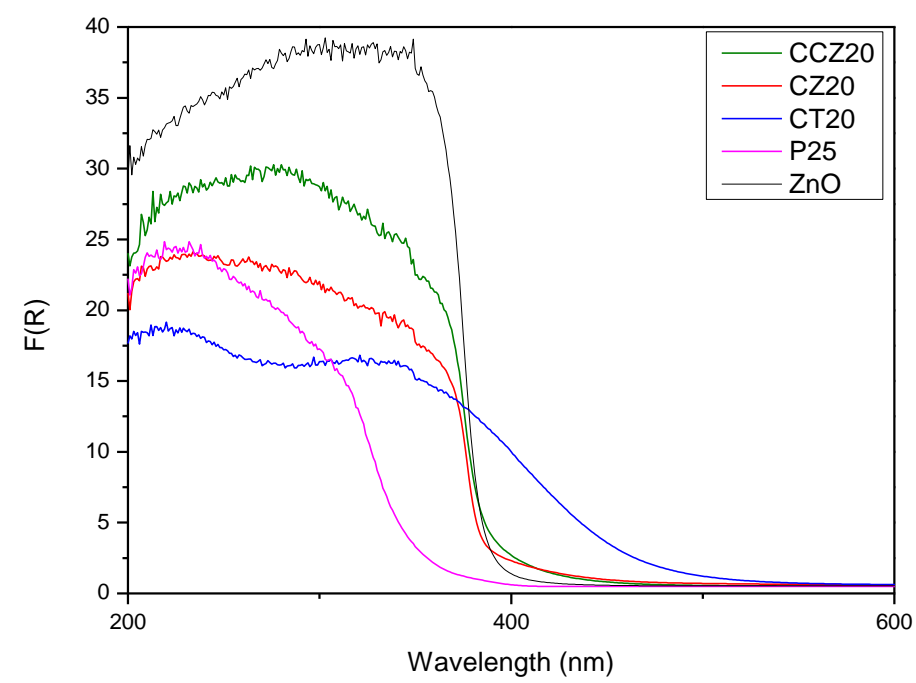

Figure 11. Kubelka-Munk function obtained by DRS analysis of Ce-doped samples.

The DRS analysis of both CZ20 and CCZ20 showed a red shift of the absorption, indicated by the small tail in the visible region and attributed to the presence of $\mathrm{CeO}_{2}$, as already reported [34]. Conversely, DRS analysis of CT20 displayed a broader visible absorption band than bare $\mathrm{TiO}_{2}$ (P25, Evonik), which was related to the achievement of $\mathrm{TiO}_{2}$ band gap engineering, and was likely related to the formation of a $\mathrm{Ce}_{\mathrm{x}} \mathrm{Ti}_{1-\mathrm{x}} \mathrm{O}_{2}$ mixed phase.

In the study, the optical properties were related to the bandgap evaluation, as reported in Table 2 and discussed in the Supporting Information File. In this case, $m=\frac{1}{2}$ was used for $\mathrm{ZnO}$ [44], while the presence of indirect transitions was accounted for $\mathrm{CeO}_{2}-\mathrm{TiO}_{2}$ mixed oxide, as the optical behaviour may be different according to the crystal phase [45], and as no defined $\mathrm{TiO}_{2}$ phase was detected. Band gap evaluation supported the red shift detected by DRS analysis, reflected in the decrease of $E_{g}$ value for CT20, compared to bare $\mathrm{TiO}_{2}$. Conversely, $\mathrm{CeO}_{2}$ doping did not considerably affect the optical properties of $\mathrm{ZnO}$, as also suggested by the Tauc plots (see Supporting Information). The Urbach plot (Figure S5 of the SI) was used to calculate the Urbach energy $E_{U}$ which has been previously used to estimate the density of electronic intra gap states in the materials [46]. Therefore, the increased value of $E_{U}$ for CZ20 and CCZ20 was related to increased number of intra gap states, when compared to pristine $\mathrm{ZnO}$. The introduction of $\mathrm{CeO}_{2}$ considerably affected the $E_{U}$ value, thereby leading to a different distribution of states in the adsorption range, also according to the synthetic method employed. A similar modification of the Urbach energy was observed for $\mathrm{CeO}_{2}$-doped $\mathrm{TiO}_{2}$, although the Urbach rule is not always obeyed by amorphous materials [46]. 
Table 2. Calculated band gap values and Urbach energies obtained via Tauc plot and Urbach plot methods, respectively.

\begin{tabular}{cccc}
\hline Sample & $\boldsymbol{m}$ & $\boldsymbol{E}_{\boldsymbol{g}}(\mathbf{e V})$ & $\boldsymbol{E}_{\boldsymbol{U}}(\mathbf{e V})$ \\
\hline $\mathrm{ZnO}$ & $\frac{1}{2}$ & 3.25 & 0.066 \\
$\mathrm{CZ20}$ & $\frac{1}{2}$ & 3.25 & 0.217 \\
$\mathrm{CCZ20}$ & $\frac{1}{2}$ & 3.24 & 0.145 \\
$\mathrm{P} 25$ & 2 & 3.26 & 0.024 \\
$\mathrm{CT20}$ & 2 & 2.39 & 0.143 \\
\hline
\end{tabular}

PL analysis showed a remarkable difference in the photoluminescence profile of CZ20, when compared to CCZ20 and bare $\mathrm{ZnO}$, both in visible and UV emission. As already reported for $\mathrm{ZnO}[47,48]$, the broad band centred at $610 \mathrm{~nm}$ detected for $\mathrm{CZ20}$ was attributed to a defect-related emission, with the high intensity likely reflecting the different size of $\mathrm{ZnO}$-based nanostructures compared to the other samples (Figure 12). Besides the introduction of visible-emitting defects, it is also possible that the presence of surfacebound C-based compounds had a preferential passivating effect over the non-radiative emission upon recombination events. The low intensity band at around $430 \mathrm{~nm}$ for CT20 was attributed to the presence of $\mathrm{CeO}_{2}$, as similarly reported for bare $\mathrm{CeO}_{2} \mathrm{NPs}$ [49], and this band was found to be red-shifted up to $460 \mathrm{~nm}$ for both CZ20 and CCZ20 (Figure 12). The presence of surface-related defects, as suggested by the broad visible band of CZ20, was related to the lower oxidative ability of the sample, when compared to CCZ20. In fact, the presence of intra states defects can result in recombination events, affecting the charge transfer and therefore the surface-related photocatalytic activity, as already reported [50,51].

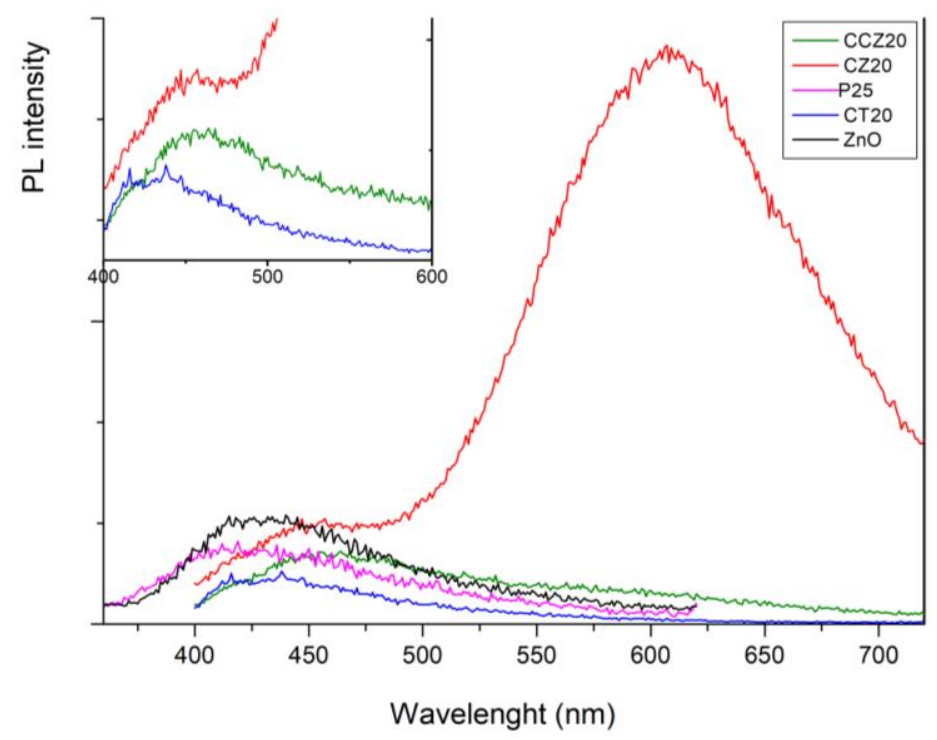

Figure 12. Photoluminescence of $\mathrm{Ce}-\mathrm{Ti}$ and $\mathrm{Ce}-\mathrm{Zn}$ composites was measured with a laser excitation wavelength of $380 \mathrm{~nm}$, while bare $\mathrm{ZnO}$ and $\mathrm{TiO}_{2}$ were investigated using a $320 \mathrm{~nm}$ laser source.

\subsection{Relevant Parameters Influencing the Photo-Catalytic Performance}

Crystallinity, intra-gap states distribution and reactant affinity were found to be relevant factors, all able to affect the overall light-responsiveness and redox properties of $\mathrm{CeO}_{2}$ composite materials.

The formation of an amorphous phase upon doping with $\mathrm{CeO}_{2}$ repressed the photocatalytic activity. In fact, the lack of photo-catalytic activity of $\mathrm{TiO}_{2}-\mathrm{CeO}_{2}$ oxides composite (CT20) was mainly attributed to the presence of an amorphous phase, suggesting the role of crystal structure in surface-related charge transfer processes as well. Moreover, the suppression of the photo-reducing activity was observed, with increased binding affinity towards C-based reagents by the composite materials. The decreased photo-oxidative 
activity was both related to a partial modification of the band gap-whose shift in the visible likely decreased the energy available to the charge transfer to donor molecules-and to the presence of surface related defects. These results suggested the relevance of the optical properties of Ce-based materials in driving successful photon-activated reactions. In addition, surface hindering by C-based residuals could have prevented the formation of reactive oxygen species. Notably, the precipitation with different methods also led to different results. The co-precipitation with carbonates (CCZ20) resulted in a higher photocatalytic activity-also owed to increased specific surface area and related to a decreased visible luminescence-when compared to the precipitation that occurred in the presence of sodium hydroxide (CZ20). The difference in the relative density of intra gap states observed was related to a difference in the photo-catalytic performance, possibly owed to the occurrence of recombination events.

\section{Materials and Methods}

\subsection{Synthesis of the Materials}

Synthesis of Nanoparticle (NPs) of $\mathrm{ZnO}$ and $\mathrm{TiO}_{2}$-Based Materials

All the $\mathrm{ZnO}$ - and $\mathrm{TiO}_{2}$-based materials were synthesized via wet chemistry precipitation method.

A $0.5 \mathrm{M}$ aqueous solution of the metal precursors $\mathrm{Zn}\left(\mathrm{NO}_{3}\right) \cdot 6 \mathrm{H}_{2} \mathrm{O}$ and of cerium ammonium nitrate [CAN, $\left.\mathrm{Ce}\left(\mathrm{NO}_{3}\right)_{6}\left(\mathrm{NH}_{4}\right)_{2}\right]$, was prepared using a $\mathrm{Zn}$ :Ce molar ratio of 4:1. By means of a peristaltic pump, the solution was progressively added to $200 \mathrm{~mL}$ of distilled water with simultaneous introduction of either a $1 \mathrm{M} \mathrm{Na}_{2} \mathrm{CO}_{3}$ or a $9 \mathrm{M} \mathrm{NaOH}$ solution, to keep the $\mathrm{pH}$ at 9 . The white-yellowish solution was then aged under continuous stirring for $20 \mathrm{~h}$ at $60{ }^{\circ} \mathrm{C}$. The obtained compound was filtered and washed with distilled water and dried for $18 \mathrm{~h}$ at $110{ }^{\circ} \mathrm{C}$. Therefore, the samples were air-annealed at $400{ }^{\circ} \mathrm{C}$ for $4 \mathrm{~h}$ and labelled CCZ20 and CZ20 if precipitated with $\mathrm{Na}_{2} \mathrm{CO}_{3}$ or $\mathrm{NaOH}$, respectively. Similarly, for the $\mathrm{CeO}_{2}-\mathrm{TiO}_{2}$ composites labelled CT20, a $0.4 \mathrm{M}$ aqueous solution of $\mathrm{TiO}\left(\mathrm{SO}_{4}\right) \times\left(\mathrm{H}_{2} \mathrm{O}\right)$ and $\mathrm{Ce}\left(\mathrm{NO}_{3}\right)_{6}\left(\mathrm{NH}_{4}\right)_{2}$ precursors was prepared using a Ti:Ce molar ratio of 4:1 using a $9 \mathrm{M}$ $\mathrm{NaOH}$ as precipitating agent.

\subsection{Photo-Catalytic Experiments}

\subsection{1. $\mathrm{CO}_{2}$ Photo-Conversion}

The photo-conversion of $\mathrm{CO}_{2}$ occurred in a flat-bottom borosilicate glass photoreactor (volume $2.8 \mathrm{~cm}^{3}$ and exposed surface $7.5 \mathrm{~cm}^{2}$ ). The catalyst dispersed in ethanol (Merck Life Science S.r.l, Milan, Italy) was spread on the bottom reactor while heating at $150{ }^{\circ} \mathrm{C}$ to obtain a homogenous film, alternating spreading and heating cycles until complete depletion of the dispersion. The reactor was then installed into a lab-made gas line [32] equipped with heated piping and a bubbler, in which a $13.3 \mathrm{CO}_{2} / \mathrm{H}_{2} \mathrm{O}$ reaction mixture was generated by bubbling a $\mathrm{CO}_{2}$ flow $(99.9 \%)$ into the bubbler filled with milliQ $\mathrm{H}_{2} \mathrm{O}$, kept at $40{ }^{\circ} \mathrm{C}$ and monitored until a constant composition was reached. The gas output was analysed through a gas chromatograph (GC, HP 6890) equipped with a thermo-conductivity detector (TCD) and a Porapak Q packed column (Figure 13). The reactions were run by locking the stabilized $\mathrm{CO}_{2} / \mathrm{H}_{2} \mathrm{O}$ gaseous mixture within the reaction and by irradiating it for $6 \mathrm{~h}$. The UVA light was generated through a UV lamp (Helios Italquartz, Milan, Italy). The light intensities were kept at $60 \mathrm{~W} / \mathrm{m}^{2}$. These values were controlled through a Delta Ohm HD 2302.0 photo-radiometer equipped with an LP 471 probe for UV (315-400 nm) light.

\subsubsection{Photocatalytic Test for Methylene Blue Degradation}

The amount of $10 \mathrm{mg}$ of $(0.05 \mathrm{M})$ either CZ20, CCZ20, or CT20 catalyst was dissolved in a $1 \cdot 10^{-5} \mathrm{M}$ methylene blue (MB) solution, with a $\mathrm{pH}$ of 7.6 under stirring conditions and exposed to a total of 60 min of dark before $1 \mathrm{~h}$ of light exposure with a $\mathrm{UV} \mathrm{Hg}$ lamp at $365 \mathrm{~nm}$ wavelength. At different times, $2 \mathrm{~mL}$ aliquots were withdrawn, and the absorption was measured by a UV-Vis spectrophotometer (Cary5000, Agilent technologies, Milan, Italy). 


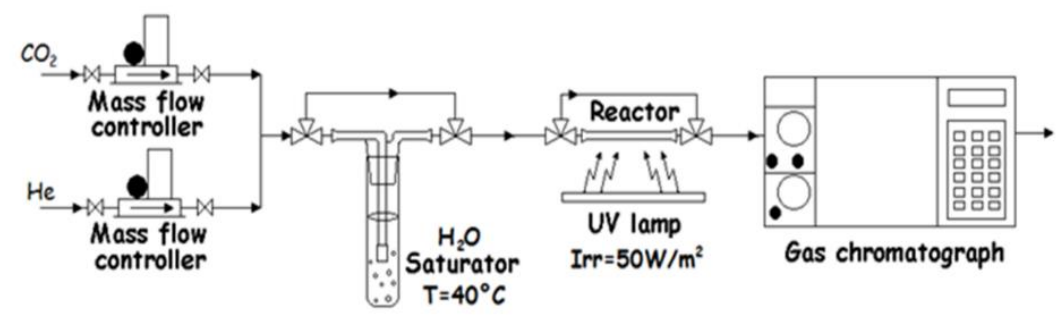

Figure 13. Lab-made gas line employed for the photo-catalytic experiment.

\subsection{Characterizations}

\subsubsection{Optical Characterization}

Vibrational spectra were recorded on pure samples. ATR spectra were obtained with a Vertex 70 spectrophotometer (Bruker, Billerica, MA, USA) equipped with the Harrick MVP2 ATR cell, with resolution $4 \mathrm{~cm}^{-1}$. FT-Raman spectra were obtained with the same instrument equipped with the RAMII accessory, by exciting with a $1064 \mathrm{~nm}$ laser, with a resolution of $4 \mathrm{~cm}^{-1}$. Diffused reflectance spectra were measured with a Cary $5000 \mathrm{UV}-\mathrm{Vis}$ spectrophotometer (Agilent Technology). The Tauc plot was obtained and employed to evaluate the bandgap value of synthesized materials. Therefore, the evaluation of the bandgap value was obtained by plotting $[F(R) h v]^{\frac{1}{m}}$ versus $h v$ as according to Equation (1) and as previously suggested [52]

$$
[F(R) h v]^{\frac{1}{m}}=K\left(h v-E_{g}\right)
$$

In which $F(R)$ is the Kubelka-Munk function, $K$ is a constant characteristic of the material, $h v$ is the energy of incident photons and $E_{g}$ is the bandgap. The value of $m$ depends on the type of transition and represents $m=\frac{1}{2}$ for direct and $m=2$ for indirect allowed transitions.

The Urbach energy $\left(E_{U}\right)$ was obtained by the Urbach relation (Equation (2)), where $f(R \infty)$ is used instead of the optical absorption coefficient $(\alpha), h$ is the Plank constant $\left(6.626 \cdot 10^{-34} \mathrm{~J} \cdot \mathrm{s}\right), \quad v$ the photon frequency in $\mathrm{s}^{-1}, \alpha_{0}$ and $E_{0}$ are temperaturedependent constants.

$$
f(R \infty)=\alpha_{0} \exp \left(\frac{h v-E_{0}}{E_{U}}\right)
$$

The $E_{U}$ is assessed from the near absorption-edge slope of $\ln (\alpha)$ vs. $h v$ [46].

Photoluminescence measurements were recorded at room temperature on powder samples using a Fluorolog F2Horiba/Jobin-Yvon spectrofluorometer (Horiba, Kyoto, Japan), with excitation at $320 \mathrm{~nm}$ or at $380 \mathrm{~nm}$.

\subsubsection{Structural Characterization}

$\mathrm{N}_{2}$ Physisorption data were recorded using a Micromeritics TriStar II Plus analyser, recording the adsorption-desorption isotherms at $-196{ }^{\circ} \mathrm{C}$. All samples were previously pre-treated in vacuum at $200{ }^{\circ} \mathrm{C}$ for $2 \mathrm{~h}$. Surface area information was taken in the $0.05-0.35 \mathrm{p} / \mathrm{p}_{0}$ range. Surface area was evaluated using the BET equation [53], while pore volume and pore size distribution on the desorption-branch isotherm using the $\mathrm{BJH}$ model [54]. X-ray diffraction (XRD) patterns were collected on a Bruker D8 Advance powder diffractometer with a sealed $\mathrm{X}$-ray tube (copper anode; operating conditions, $40 \mathrm{kV}$ and $40 \mathrm{~mA}$ ) and a $\mathrm{Si}(\mathrm{Li})$ solid state detector (Sol-X) set to discriminate the $\mathrm{Cu} \mathrm{K} \alpha$ radiation. Data scans were performed in the $2 \theta$ range $5-75^{\circ}$ with $0.02^{\circ}$ step size and counting times of $3 \mathrm{~s} /$ step. Quantitative phase analysis and crystallite size determination were performed using the Rietveld method, as implemented in the TOPAS v.4 program (Bruker AXS, Bruker, Billerica, MA, USA) using the fundamental parameters approach for line-profile fitting. The determination of the crystallite size was accomplished by the Double-Voigt approach and calculated as volume-weighted mean column heights based on integral breadths of peaks. 
Morphology and composition were examined by Field Emission Gun Electron Scanning Microscopy (FE-SEM) LEO 1525 ZEISS (Zeiss, Oberkochen, Germany), after metallization with chromium. Elemental composition and chemical mapping were determined using a Quantax EDSFT (Bruker, Billerica, MA, USA).

\subsubsection{Temperature Programmed Analysis}

Temperature programmed reduction (TPR) was performed on lab-made reaction equipment, placing $50 \mathrm{mg}$ of samples into a U-shaped quartz reactor and heating from r.t. to $800{ }^{\circ} \mathrm{C}$ at $10{ }^{\circ} \mathrm{C} / \mathrm{min}$, in a $5 \% \mathrm{H}_{2} / \mathrm{Ar}$ gas mixture ( $40 \mathrm{~mL} / \mathrm{min}$ flow at STP). $\mathrm{A} \mathrm{MgClO}_{4}$ trap was used to remove water from the outcoming flow, and the gas was analysed through a Gow-Mac TCD. He-TPD were performed with the same procedure using a pure He as carrier gas $\left(40 \mathrm{~mL} / \mathrm{min}\right.$ at STP) instead, without the $\mathrm{MgClO}_{4}$ trap. $\mathrm{CO}_{2}$-TPD were performed similarly after pre-treating the sample in He flow $(40 \mathrm{~mL} / \mathrm{min} \mathrm{STP})$ at $110^{\circ} \mathrm{C}$ for $1 \mathrm{~h}$, to remove surface-adsorbed species. The sample was exposed to pure $\mathrm{CO}_{2}$ at r.t. in a sequence of pulses up to saturation. Finally, the sample was heated from r.t. to $800{ }^{\circ} \mathrm{C}$ at $10{ }^{\circ} \mathrm{C} / \mathrm{min}$ in He flow, and the outcoming gases analysed without the $\mathrm{MgClO}_{4}$ trap.

\section{Conclusions}

In this study, we assessed the structural and optical modifications-as well as their effect on the photo-catalytic activity-of $\mathrm{CeO}_{2}$-doped wide band gap semiconductors. We concluded that the introduction of $20 \%$ mol Ce effects on the structural and optical behaviour was dependent on the semiconductor employed; either $\mathrm{ZnO}$ or $\mathrm{TiO}_{2}$. The lanthanide to metal interaction resulted in a consistent modification of $\mathrm{TiO}_{2}$ crystal structure, showing an amorphous phase, which also resulted in increased surface area and modified bandgap, as suggested by the enhanced visible light absorption. The presence of Ce in $\mathrm{ZnO}$-based materials was mainly detected as cerianite nanocrystallites dispersed in the $\mathrm{ZnO}$ wurtzite crystal structure, associated to poor red shift in the light absorption and no bandgap modification. The synthesis of the composites using $\mathrm{NaOH}$ as a precipitating agent was also related to the detectable presence of surface-adsorbed carbonates. The employment of different precipitating agents was also reflected on the size and morphology of $\mathrm{ZnO}$-based materials, as well as on the distribution and abundance of $\mathrm{Ce}^{4+}$ states in the material. The affinity for C-based compounds, resulting from the introduction of $\mathrm{CeO}_{2}$, together with the bandgap modification, was considered as the main limiting factor preventing the effective photo-catalytic conversion of $\mathrm{CO}_{2}$ by both $\mathrm{CeO}_{2}-\mathrm{TiO}_{2}$ and $\mathrm{CeO}_{2}-\mathrm{ZnO}$ composites. The decreased photo-degradation of $\mathrm{MB}$ was overall attributed to a decreased crystallinity, and to the presence of surface-related recombination events, together with a low photo-activity of $\mathrm{CeO}_{2}$ in the mild irradiating and temperature conditions employed.

In conclusion, $\mathrm{CeO}_{2}-\mathrm{ZnO}$-mixed oxides resulted in being more appropriate for photooxidizing reactions compared with the photo reduction of $\mathrm{CO}_{2}$ in mild temperature and pressure conditions.

Supplementary Materials: The following are available online at https://www.mdpi.com/article/ 10.3390/catal11101209/s1, Figure S1: $\mathrm{CO}_{2}$ photoreduction, Figure S2: ZnO SEM, Figure S3: pore distribution, Figure S4: Tauc plot, Figure S5: Urbach plot.

Author Contributions: Conceptualization, G.F. And D.Z.; methodology, E.G., A.D.M., G.C. (Giuseppina Cerrato), G.C. (Giuseppe Cruciani) and A.G.; Data revision F.M. and M.S. All authors have read and agreed to the published version of the manuscript.

Funding: This research received no external funding.

Conflicts of Interest: The authors declare no conflict of interest. 


\section{References}

1. Boyjoo, Y.; Sun, H.; Liu, J.; Pareek, V.K.; Wang, S. A review on photocatalysis for air treatment: From catalyst development to reactor design. Chem. Eng. J. 2017, 310, 537-559. [CrossRef]

2. Olivo, A.; Zanardo, D.; Ghedini, E.; Menegazzo, F.; Signoretto, M. Solar Fuels by Heterogeneous Photocatalysis: From Understanding Chemical Bases to Process Development. Chemengineering 2018, 2, 42. [CrossRef]

3. Habisreutinger, S.N.; Schmidt-Mende, L.; Stolarczyk, J.K. Photocatalytic Reduction of $\mathrm{CO}_{2}$ on $\mathrm{TiO}_{2}$ and Other Semiconductors. Angew. Chem. Int. Ed. 2013, 52, 7372-7408. [CrossRef] [PubMed]

4. Bai, S.; Jiang, J.; Zhang, Q.; Xiong, Y. Steering charge kinetics in photocatalysis: Intersection of materials syntheses, characterization techniques and theoretical simulations. Chem. Soc. Rev. 2015, 44, 2893-2939. [CrossRef] [PubMed]

5. Herrmann, J.-M. Heterogeneous photocatalysis: Fundamentals and applications to the removal of various types of aqueous pollutants. Catal. Today 1999, 53, 115-129. [CrossRef]

6. Ghedini, E.; Menegazzo, F.; Manzoli, M.; Di Michele, A.; Puglia, D.; Signoretto, M. Multifunctional and Environmentally Friendly $\mathrm{TiO}_{2}-\mathrm{SiO}_{2}$ Mesoporous Materials for Sustainable Green Buildings. Molecules 2019, 24, 4226. [CrossRef]

7. Auer, G.; Woditsch, P.; Westerhaus, P.; Kischkewitz, J.; Griebler, W.-D.; De Liedekerke, M. White Pigments. In Inorganic Pigments; Wiley-VCH: Weinheim, Germany, 2012; Volume 27, pp. 257-289.

8. Zhang, W.; Hu, Y.; Ma, L.; Zhu, G.; Wang, Y.; Xue, X.; Chen, R.; Yang, S.; Jin, Z. Progress and Perspective of Electrocatalytic CO 2 Reduction for Renewable Carbonaceous Fuels and Chemicals. Adv. Sci. 2018, 5, 1-24. [CrossRef]

9. Özgür, Ü.; Alivov, Y.I.; Liu, C.; Teke, A.; Reshchikov, M.A.; Doğan, S.; Avrutin, V.; Cho, S.-J.; Morkoç, H. A comprehensive review of ZnO materials and devices. J. Appl. Phys. 2005, 98, 041301. [CrossRef]

10. Li, Y.; Xie, W.; Hu, X.; Shen, G.; Zhou, X.; Xiang, Y.; Zhao, X.; Fan, P. Comparison of Dye Photodegradation and its Coupling with Light-to-Electricity Conversion over $\mathrm{TiO}_{2}$ and ZnO. Langmuir 2010, 26, 591-597. [CrossRef]

11. Khodja, A.A.; Sehili, T.; Pilichowski, J.-F.; Boule, P. Photocatalytic degradation of 2-phenylphenol on $\mathrm{TiO}_{2}$ and $\mathrm{ZnO}_{\text {in aqueous }}$ suspensions. J. Photochem. Photobiol. Chem. 2001, 141, 231-239. [CrossRef]

12. Shaheed, M.A.; Hussein, F.H. Preparation and Applications of Titanium Dioxide and Zinc Oxide Nanoparticles. J. Environ. Anal. Chem. 2015, 2, 1-2. [CrossRef]

13. Rajendran, S.; Khan, M.M.; Gracia, F.; Qin, J.; Gupta, V.K.; Arumainathan, S. Ce ${ }^{3+}$-ion-induced visible-light photocatalytic degradation and electrochemical activity of $\mathrm{ZnO} / \mathrm{CeO}_{2}$ nanocomposite. Sci. Rep. 2016, 6, 1-11. [CrossRef] [PubMed]

14. Li, F.B.; Li, X.Z.; Ao, C.H.; Lee, S.C.; Hou, M.F. Enhanced photocatalytic degradation of VOCs using $\mathrm{La}^{3+}-\mathrm{TiO}_{2}$ catalysts for indoor air purification. Chemosphere 2005, 59, 787-800. [CrossRef] [PubMed]

15. Liu, B.; Zhao, X.; Zhang, N.; Zhao, Q.; He, X.; Feng, J. Photocatalytic mechanisms of $\mathrm{CeO}_{2}-\mathrm{TiO}_{2}$ films prepared by magnetron sputtering under UV and visible light. Sur. Sci. 2005, 595, 203-211. [CrossRef]

16. Reinhardt, K.; Winkler, H. Cerium Mischmetal, Cerium Alloys, and Cerium Compounds. In Ullmann's Encyclopedia of Industrial Chemistry; Wiley-VCH: Weinheim, Germany, 2012; Volume 8, pp. 41-54.

17. Abdullah, H.; Khan, M.R.; Pudukudy, M.; Yaakob, Z.; Ismail, N.A. $\mathrm{CeO}_{2}-\mathrm{TiO}_{2}$ as a visible light active catalyst for the photoreduction of $\mathrm{CO}_{2}$ to methanol. J. Rare Earth 2015, 33, 1155-1161. [CrossRef]

18. Skorodumova, N.V.; Ahujia, R.; Simak, S.I.; Abrikosov, I.A.; Johansson, B.; Lundqvist, B.I. Electronic, bonding and optical properties of $\mathrm{CeO}_{2}$ and $\mathrm{Ce}_{2} \mathrm{O}_{3}$ from first principle. Phys. Rev. B 2001, 64, 1-9. [CrossRef]

19. Tsunekawa, S.; Wang, J.-T.; Kawazoe, Y. Lattice constant and electron gap energies of nano- and subnano-sized cerium oxides from the experiments and from first-principles calculation. J. Alloys Compd. 2006, 408, 1145-1148. [CrossRef]

20. Sherly, E.D.; Vijaya, J.J.; Kennedy, L.J. Effect of the $\mathrm{CeO}_{2}$ coupling on the structural, optical photocatalytic properties of ZnO nanoparticles. J. Mol. Struct. 2015, 1099, 114-125. [CrossRef]

21. Zholobak, N.M.; Ivanov, V.K.; Shcherbakov, A.B.; Shaporev, A.S.; Polezhaeva, O.S.; Baranchikov, A.Y.; Spivak, N.Y.; Tretyakov, Y.D. UV-shielding property, photocatalytic activity and photocytotoxicity of ceria colloid solutions. J. Photochem. Photobiol. B Biol. 2011, 102, 32-38. [CrossRef]

22. Yousefi, M.; Amiri, M.; Azimirad, R.; Moshfegh, A.Z. Enhanced photoelectrochemical activity of Ce doped ZnO nanocomposite thin films under visible light. J. Electroanal. Chem. 2011, 661, 106-112. [CrossRef]

23. Paganini, M.C.; Dalmasso, D.; Gionco, C.; Polliotto, V.; Mantilleri, L.; Calza, P. Beyond $\mathrm{TiO}_{2}$ : Cerium-doped zinc oxide as a new photocatalyst for the photodegradation of persistent pollutants. Chem. Sel. 2016, 1, 3377-3383. [CrossRef]

24. Rezaei, M.; Habibi-Yangjeh, M. Simple and large-scale refluxing method for preparation of Ce-doped ZnO nanostructures as highly efficient photocatalyst. Appl. Surf. Sci. 2013, 265, 591-596. [CrossRef]

25. Rezaei, M.; Habibi-Yangjeh, A. Microwave-assisted preparation of Ce-doped ZnO nanostructures as an efficient photocatalyst. Mater. Lett. 2013, 110, 53-56. [CrossRef]

26. Murugadoss, G.; Ma, G.; Ning, X.; Kumar, M.R. Selective metal ions doped $\mathrm{CeO}_{2}$ nanoparticles for excellent photocatalytic activity under sun light and supercapacitor application. Inorg. Chem. Commun. 2019, 109, 107577. [CrossRef]

27. Ma, T.-Y.; Yuan, Z.-Y.; Cao, J.-L. Hydrangea-Like Meso-/Macroporous ZnO-CeO 2 Binary Oxide Materials: Synthesis, Photocatalysis and CO Oxidation. Eur. J. Inorg. Chem. 2010, 2010, 716-724. [CrossRef]

28. Silva, A.M.T.; Silva, C.G.; Dražić, G.; Faria, J.L. Ce-doped $\mathrm{TiO}_{2}$ for photocatalytic degradation of chlorophenol. Catal. Today 2009, 144, 13-18. [CrossRef] 
29. Kundu, S.; Ciston, J.; Senanayake, S.D.; Arena, D.A.; Fujita, E.; Stacchiola, D.; Barrio, L.; Navarro, R.M.; Fierro, J.L.G.; Rodriguez, J.A. Exploring the Structural and Electronic Properties of $\mathrm{Pt} /$ Ceria Modified $\mathrm{TiO}_{2}$ and Its Photocatalytic Activity for Water Splitting under Visible Light. J. Phys. Chem. C 2012, 116, 14062-14070. [CrossRef]

30. Fiorenza, R.; Bellardita, M.; D’Urso, L.; Compagnini, G.; Palmisano, L.; Scirè, S. Au/ $\mathrm{TiO}_{2}-\mathrm{CeO}_{2}$ Catalysts for Photocatalytic Water Splitting and VOCs Oxidation Reactions. Catalysts 2016, 6, 121. [CrossRef]

31. Dias, B.V.; Tractz, G.T.; Viomar, A.; Maia, G.A.R.; Da Cunha, M.T.; Rodrigues, P.R.P. Photoelectrochemical Behaviour of the Cell FTO $/ \mathrm{TiO}_{2} / \mathrm{CeO}_{2} / \mathrm{N} 719$ Obtained from the Pechini and Precipitation of Cerium Oxide Methods. J. Electron. Mater. 2018, 47, 5556-5563. [CrossRef]

32. Olivo, A.; Trevisan, V.; Ghedini, E.; Pinna, F.; Bianchi, C.L.; Naldoni, A.; Cruciani, G.; Signoretto, M. CO 2 photoreduction with water: Catalyst and process investigation. J. $\mathrm{CO}_{2}$ Utiliz. 2015, 12, 86-94. [CrossRef]

33. Wang, L.; Ji, Z.; Lin, J.; Li, P. Preparation and optical and photocatalytic properties of Ce-doped ZnO microstructures by simple solution method. Mater. Sci. Semicond. Process. 2017, 71, 401-408. [CrossRef]

34. Cuscò, R.; Alarcón-Lladó, E.; Ibáñez, J.; Artús, L.; Jiménez, J.; Wang, B.; Callahan, M.J. Temperature dependence of Raman scattering in ZnO. Phys. Rev. B 2007, 75, 165202. [CrossRef]

35. Loridant, S. Raman spectroscopy as a powerful tool to characterize ceria-based catalysts. Catal. Today 2021, 373, 98-111. [CrossRef]

36. Shalish, I.; Temkin, H.; Narayanamurti, V. Size-dependent surface luminescence in ZnO nanowires. Phys. Rev. B 2004, 69, 245401. [CrossRef]

37. Shannon, R.D. Revised Effective Ionic Radii and Systematic Studies of Interatomic Distances in Halides and Chalcogenides. Acta Cryst. 1976, A32, 751-767. [CrossRef]

38. Watanabe, S.; Ma, X.; Song, C. Characterization of Structural and Surface Properties of Nanocrystalline $\mathrm{TiO}_{2}-\mathrm{CeO}_{2} \mathrm{Mixed}$ Oxides by XRD, XPS, TPR, and TPD. J. Phys. Chem. C 2009, 113, 14249-14257. [CrossRef]

39. Menegazzo, F.; Pizzolitto, C.; Ghedini, E.; Di Michele, A.; Cruciani, G.; Signoretto, M. Development of La Doped Ni/CeO 2 for $\mathrm{CH}_{4} / \mathrm{CO}_{2}$ Reforming. J. Carbon Res. 2018, 4, 60. [CrossRef]

40. Zanardo, D.; Ghedini, E.; Menegazzo, F.; Cattaruzza, E.; Manzoli, M.; Cruciani, G.; Signoretto, M. Titanium Dioxide-Based Nanocomposites for Enhanced Gas-Phase Photodehydrogenation. Materials 2019, 12, 3093. [CrossRef] [PubMed]

41. Mino, L.; Spoto, G.; Ferrari, A.M. $\mathrm{CO}_{2}$ Capture by $\mathrm{TiO}_{2}$ Anatase Surfaces: A Combined DFT and FTIR Study. J. Phys. Chem. C 2014, 118, 25016-25026. [CrossRef]

42. Gankanda, A.; Cwiertny, D.M.; Grassian, V.H. Role of Atmospheric $\mathrm{CO}_{2}$ and $\mathrm{H}_{2} \mathrm{O}$ Adsorption on $\mathrm{ZnO}$ and $\mathrm{CuO}$ Nanoparticle Aging: Formation of New Surface Phases and the Impact on Nanoparticle Dissolution. J. Phys. Chem. C 2016, $120,19195$. [CrossRef]

43. Dollimore, D.; France, J.A.; Krupay, B.W.; Whitehead, R. Kinetic aspects of the thermal decomposition of zinc carbonate. Thermochim. Acta 1980, 36, 343-349. [CrossRef]

44. Sáenz-Trevizo, A.; Amézaga-Madrid, P.; Pizá-Ruiz, P.; Antúnez-Flores, W.; Miki-Yoshida, M. Optical Band Gap Estimation of ZnO Nanorods. Mater. Res. 2016, 19, 33-38. [CrossRef]

45. Reyes-Coronado, D.; Rodriguez-Gattorno, G.; Espinosa-Pesqueira, M.E.; Cab, C.; de Coss, R.; Oskam, G. Phase-pure TiO 2 nanoparticles: Anatase, brookite and rutile. Nanotechnology 2008, 19, 1-10. [CrossRef] [PubMed]

46. Studenyak, I.; Kranjčec, M.; Kurik, M. Urbach Rule in Solid State Physics. Int. J. Opt. Appl. 2014, 4, 76-78.

47. Lim, W.F.; Quah, H.J.; Hassan, Z.; Radzali, R.; Zainal, N.; Yam, F.K. Alteration of structural and optical properties in quaternary Al0.1In0.1Ga0.8N films using ultraviolet assisted photo-electrochemical etching route. J. Alloys Compd. 2015, 649, 337-347. [CrossRef]

48. Tam, K.H.; Cheung, C.K.; Leung, Y.H.; Djurisic, A.B.; Ling, C.C.; Beling, C.D.; Fung, S.; Kwok, W.M.; Chan, W.K.; Phillips, D.L.; et al. Defects in ZnO Nanorods Prepared by a Hydrothermal Method. J. Phys. Chem. B 2006, 110, 20865-20871. [CrossRef]

49. Djurišić, A.B.; Leung, Y.H.; Tam, K.H.; Hsu, Y.F.; Ding, L.; Ge, W.K.; Zhong, Y.; Wong, K.S.; Chan, W.K.; Tam, H.L.; et al. Defect emissions in $\mathrm{ZnO}$ nanostructures. Nanotechnology 2007, 18, 1-8. [CrossRef]

50. Malleshappa, J.; Nagabhushana, H.; Sharma, S.C.; Vidya, Y.S.; Anantharaju, K.S.; Prashantha, S.C.; Daruka Prasad, B.; Raja Naika, H.; Lingaraju, K.; Surendra, B.S. Leucas aspera mediated multifunctional $\mathrm{CeO}_{2}$ nanoparticles: Structural, photoluminescent, photocatalytic and antibacterial properties. Spectrochim. Acta Part A Mol. Biomol. Spectrosc. 2015, 149, 452-462. [CrossRef]

51. Guo, M.Y.; Ng, A.M.C.; Liu, F.; Djurisic, A.B.; Chan, W.K.; Su, H.; Wong, K.S. Effect of Native Defects on Photocatalytic Properties of ZnO. J. Phys. Chem. C 2011, 115, 11095-11101. [CrossRef]

52. Yoong, L.S.; Chong, F.K.; Dutta, B.K. Development of copper-doped $\mathrm{TiO}_{2}$ photocatalyst for hydrogen production under visible light. Energy 2009, 34, 1652-1661. [CrossRef]

53. Brunauer, S.; Emmett, P.H.; Teller, E. Adsorption of Gases in Multimolecular Layers. J. Am. Chem. Soc. 1938, 60, 309-319. [CrossRef]

54. Barrett, E.P.; Joyner, L.S.; Halenda, P.P. The Determination of Pore Volume and Area Distributions in Porous Substances. I. Computations from Nitrogen Isotherms. J. Am. Chem. Soc. 1951, 73, 373-380. 